\title{
Early and Timing restoration will be an effective way to repair the riparian habitat
}

\author{
Tengfei Yan ${ }^{1}$, Kremenetska Oleksiivna ${ }^{2}$, Songlin $\mathrm{He}^{3}$, Biyang Zhang ${ }^{1}$, Zelong $\mathrm{Yu}^{1}$, Qiang \\ $\mathrm{Hu}^{1}$, Xiangpeng Liang ${ }^{1}$, Manyi $\mathrm{Fu}^{1}$, and Zhen $\mathrm{Wang}^{1}$ \\ ${ }^{1}$ Xinyang Agriculture and Forestry University \\ ${ }^{2}$ Sumy National Agrarian University \\ ${ }^{3}$ Henan Institute of Science and Technology
}

August 24, 2021

\begin{abstract}
The impoundment of dams can significantly alter shorelines, hydrological regime, sediment and nutrient cycle. With the completion of Chushandian reservoir dam, land use types around the reservoir have been profoundly affected by flooding. As yet, the characteristics of soil properties on different land use types in new built reservoir have not been fully elaborated. In this work, we investigated the variation of soil physical and chemical properties at distance scale for different land use types after short-term inundating. Soil physical properties, chemical properties, soil particle structure were determined. This study reported that short-term inundating had impacts on soil physical and chemical properties of different land use types. Our results indicated that the soil physical and chemical properties at $0 \mathrm{~m}$ site of each land use types may be mainly affected by the nutrient status of overlying water. The soil TN, TC of all land use types decreased gradually with the increase of distance from river bank, among which the contents of TN and TC at W2 were significantly higher than those at other sites. Compared with woodland, both abandoned cropland and grass land showed the phenomenon of soil particle loss and nutrient leaching. The characteristics of low NH4-N and high NO3-N were observed in the woodland after flooding, which may be related to denitrification. The main influencing factor is soil microbial activity at W20. The main influencing factor is soil nutrient status At W2. And at abandoned cropland and grassland, the main influencing factor is soil physical properties. The response of different land use types to short-term flooding may be mainly related to the degree of vegetation coverage. Abandoned cropland showed stronger resilience, while grassland showed stronger tolerance. The present study suggested that early and timing restoration will be an effective way to repair the riparian habitat.
\end{abstract}

\section{Hosted file}

Tengfei_Yan_manuscript.doc available at https://authorea.com/users/431537/articles/535025early-and-timing-restoration-will-be-an-effective-way-to-repair-the-riparian-habitat 